any existing drift of the æether relatively to the sun. The existence of such molecules in space may be accounted for by their continual expulsion from the sun and stars, and it is obvious that, if the æther is at all capable of offering any resistance to the passage of such materials, the molecules would eventually take up the motion of the æther relative to the sun. Then to determine the motion of the resisting medium would be, in any case, to determine the relative motion of the æther. Owing to their very small density comets would be the most likely celestial bodies to indicate the existence of the resisting medium.

Assuming that the majority of comets really have elliptic orbits, and are therefore following the sun through space, the effect of a resisting medium would be to drag their aphelia to the rear of the sun, i.e. towards the anti-apex of the sun's path.

As bright comets probably owe their conspicuousness to the fact that they are surrounded by enormous, verv tenuous envelopes of gaseous material, the resisting action should be more evident on them, and on plotting the aphelia of a number of comets Prof. Pickering finds that this is the case. The aphelia of the brighter elliptical comets do appear to concentrate in a particular region of the sky, and this antiapex in regard to the resisting medium coincides pretty closely with the solar anti-apex. There are some inconsistencies still to be accounted for, but on the whole it would appear that these cometary aphelia are drapged to the rearward of the sun, thus indicating a drift of the resisting medium, and therefore of the æther, in regard to the sun.

Observations of Comers.-The Comptes rendus for November II (No. 20) contain reports, from many observatories, of observations of comets I9I2b (Tuttle's) and I912c (Borrelly's). M. Borrelly states that on November 3 the nucleus of his comet appeared to be asymmetricallv placed in the coma, while M. Coggia on November 4 and 8 could detect no definite nucleus but only a gradual brightening towards the centre; in this he is confirmed by M. Esmiol, of the Marseilles Observatory. Generally the comet is reported as a round nebulosity, with a very indistinct or no nucleus, and no tail; during the early part of the month the magnitude was about 9 or Io, and according to the ephemeris it is now about two-thirds as bright, and will continue to decrease.

\section{METEOROLOGY AT THE BRITISH} ASSOCIATION.

THE leading feature of meteorological interest in the proceedings at Dundee was the joint discussion with Section M, Agriculture, on the application of meteorological information to agricultural practice.

Dr. Shaw said that the annual loss to this country through unfavourable weather might be put at $20,000,000 l$., and as forecasts must ultimately be forecasts for the whole globe, the amount of the loss some portion of which meteorologists aimed at saving for the British Empire far exceeded the estimate mentioned. But apart from forecasts, which aimed at saving by preventive precautions, there was probably much to be done in increasing efficiency by the application of our present knowledge of climate. In this connection the meteorologist wished to learn from the agriculturist if he could make use of meteorological statistics, and in what form he wished the statistics to be presented to him. There were, moreover, certain questions the answers to which would render possible considerable economies, and perhaps save the aspiring farmer many disastrous experiences. NO. 2248, VOL. 9o]
Such questions were: "What is the effect of climate on crops?" "What deviations from the normal values of the meteorological elements constitute a good or bad farmer's year?" Mr. R. H. Hooker had made some progress towards providing an answer to the first question in his paper on correlation between weather and crops, and he himself had investigated the relation between autumn rainfall and yield of wheat. Recently also Unstead had reached interesting conclusions in connection with the world's wheat crop, the polar limit of which depended upon the accumulated temperature and the duration of daylight in the summer months.

Mr. Watt communicated some results which he had obtained for the connection between rainfall and temperature, and the yield of crops in Forfarshire. $\mathrm{He}$ found that a dry June and July were favourable to the potato crop, and warmth during that period was also desirable. For oats, however, a cool June was decidedly favourable.

Dr. E. J. Russell spoke of the effect of climate on plant life by direct action on the plant itself, and indirectly through its action on the quality and texture of the soil. Heavy rain washed out the nitrates in the soil, while hot dry weather and frost conserved them. At the end of the summer of Igrr the soil contained $3 \frac{1}{2}$ times the usual amount of nitrates, but the heavy rains of the succeeding autumn and winter washed out nine-tenths of them.

Mr. R. M. Barrington, speaking as a practical farmer, testified to the great utility of local observations in conjunction with the reports of the Meteorological Office, and expressed the opinion that meteorology ought to be taught to every budding farmer.

On the Tuesday morning Prof. Turner gave an account of his investigation of periodicities in earthquake phenomena. He found evidence of a real period of about 15 months and indications of a period of $11^{\circ} 7^{6}$ months, which was also found in the rainfall at Greenwich. He communicated also a paper by $\mathrm{Mr}$. J. I. Craig, in which the author showed that Schuster's method of the periodogram and the method of correlation were practically identical.

Mr. E. M. Wedderburn gave an account of his investigations of the temperature conditions in the Madüsee in Pomerania and in Loch Earn. In both cases the temperature changes were found to be oscillatory and capable of explanation on the assumption that the motion of the water in the lake was in opposite directions above and below the level of maximum rate of change of density.

Miss White read two papers on the results for wind and temperature obtained at the upper air station at Glossop Moor during 1908, I909.

She found that the average velocity of the wind changed from $5^{\circ} \circ \mathrm{m}$.p.s. (metres per second) at ground level $(335 \mathrm{~m}$.$) , to \mathrm{Ir} 8 \mathrm{~m}$.p.s. at rooo m., and to I3.6 m.p.s. at $2000 \mathrm{~m}$. above mean sea-level. The velocities at all heights were greater in winter than in summer, and greater also for occasions when the surface pressure was below the average than for occasions when it was above. The rate of increase of velocity was greater for westerly than for easterly winds. At the surface it was approximately the same, 5 m.p.s. in both cases, but at $2000 \mathrm{~m}$. altitude the velocity was 16 m.p.s. for westerly winds compared with i2 m.p.s. for easterly. On the average, the theoretical value of the gradient wind calculated from the pressure distribution was reached by the actual wind at an altitude of $650 \mathrm{~m}$., or $300 \mathrm{~m}$. above ground level.

In the second paper on temperature, the rate of fall with height was found to diminish from $8^{\circ} 5^{\circ} \mathrm{C}$. per $\mathrm{km}$. near the surface to $4.3^{\circ} \mathrm{C}$. per $\mathrm{km}$. at 
$2000 \mathrm{~m}$. altitude. The height at which the mean annual temperature is $0^{\circ} \mathrm{C}$. was found to be about $2100 \mathrm{~m}$. The temperatures in the upper air were higher, both in winter and in summer, over regions of high pressure than over regions of low pressure.

Both papers contained much valuable and interesting information, and Prof. Petavel expressed the hope that they would be utilised by aviators. The probable conditions in the upper air could be forecasted from the surface conditions by using the average values given by Miss White.

The report of the joint committee on the investigation of the upper air contains the results obtained at Mungret College, Limerick, during the past year, from which it appears that the height of the stratosphere over Ireland is very nearly the same as it is over England and the Continent. In speaking on the report, Rev. W. O'Leary, S.J., who has conducted the work at Mungret College, expressed the desire felt by those engaged in this work for definite instructions as to the type of weather in which ascents might be made with a fair chance of the balloon and instruments being recovered.

A grant of $50 l$. was made to the committee for the extension of the work during 1912-13, when it is hoped that ascents will be made over the North Atlantic.

\section{EDUCATION AT THE BRITISH ASSOCIATION.}

THE presidential address was devoted to the consideration of the progress made in the develop. ment of an objective standard in education. It was therefore a departure from the type of address with which this section has been opened, and as such it marks a distinct stage in the evolution of the science of education. Prof. Adams's statement was distinguished by its moderation. He realises the difficulties, but is not unhopeful of their being overcome. Whether the psychologists will be quite happy about his statement that education has captured their subject is not quite certain, but, much as education owes to psychology, there can be little doubt that psychology is vastly in the debt of education. But we are only at the beginning of the scientific study of the problem of education, which, by reason of its special aims and restricted field, must ultimately acquire that definiteness which we recognise as belonging to the older sciences represented in the British Association.

Most closely connected with the subject of the presidential address was the meeting devoted to the psychological processes underlying reading and writing. A sectional committee had reported upon the subject and arranged for papers to be read. Mr. F. Smith dealt with the process as it takes place in the practised reader, and Mr. Dumville with the learner. Mr. Dumville's paper was in the main a defence of the so-called "Look and say" method of teaching to read -the method, that is to say, which deals with whole words first, leaving their analysis to the time when the learner has realised the meaningful character of the printed page and is anxious to get at it. The natural tendency to analysis comes out in the effort to deal with new word-forms, and the teacher may profitably act as guide. Miss Foxley's experiments had led her to the same conclusions as those reached by $\mathrm{Mr}$. Dumville. Dr. Brown and Dr. Rusk followed with accounts of movement in writing. The pedagogical consequences of these analyses were not, however, discussed.

Friday's meeting was devoted to the burning question of the relation of the school to future vocation.
Mr. J. W. Peck, until recently clerk to the Edinburgh School Board, gave a lucid account of the way in which his authority attempted to meet the vocational call in the evening continuation schools of the city. Out of the 17,000 folk between fourteen and eighteen years of age, 12,000 were actually reached by their scheme-a purely voluntary one, as they have not put into operation the compulsory powers vested in them by the Act of 1908. The freedom of choice left to the pupils produced a want of balance in their work; the subjects having a directly utilitarian value were unduly favoured. Thus only $2 \frac{1}{2}$ per cent. took courses in civics, and only ro per cent. pursued English studies. Mr. Peck favoured some form of compulsion, as only in that way would they reach the outstanding 5000 , and a reasonable curriculum be ensured. Mr. Holland showed us some of the difficulties of relating education to vocation, at any rate in the day school. The division of labour was so minute in his own district that a man might spend his working life on making the ninety-fifth part of a shoe. How exactly the difficulty was to be overcome Mr. Holland was not quite clear, although he was convinced that school work should, and could, be made more meaningful to the pupils.

Miss Faithfull spoke with conviction against allowing education to be determined by vocation. Her plea was for a liberal education in the old-fashioned sense of that word. She would deny that a training could be both liberal and vocational. Her voice was, however, a solitary one. Miss Burstall, of the Manchester High School, was wholeheartedly in favour of giving a vocational turn to the education of girls. She had worked in that direction in her own school with unqualified success. School was no longer a bore to girls who had at one time chafed under the exercises which seemed to lead nowhere. Mr. Reid spoke of the question from the point of view of the engineer, and $\mathrm{Mr}$. Ferguson told the section of the successful effort to "liberalise" the vocation of cardboard-box makers in the Bourneville works.

An interesting review of the present position of mathematical teaching was opened by Dr. T. P. Nunn, followed by Drs. Pinkerton and Milne, and Mr. Eggar. The first three speakers were at one in their defence of the attempt to humanise school mathematics, even at the expense of dexterity in dealing with complex mathematical expressions-at any rate, in the initial stages. Mr. Eggar voiced a doubt as to the position in geometry, and Prof. Silvanus Thompson supported him in saying that reformers had often gone too far -further than Prof. Perry himself ever intended. Both Prof. Thompson and Principal Griffiths felt that a definite mathematical quality had been weakened or lost in the abandonment of Euclid, and that this loss would continue until some adequate substitute had been found.

Scotch experience in the matter of leaving certificates was described by Mr. Strong and Mr. Donne, and the Scotch Education Department was attacked by Principal Sir J. Donaldson, who in a previous discussion had advocated individual liberty in the matter of spelling.

The section received various reports from committees on (I) school books and eyesight, (2) the curriculum and organisation of industrial and Poor Law schools, and (3) the overlapping between school and university. It is hoped that the "books and eyesight" report will be circulated very widely amongst education authorities. It is clear, too, that there is much that needs amending in our industrial schools, especially perhaps in those which are run on the subscriptions of the charitable, and are therefore less directly under public control.

NO. 2248 , VOL. 9o] 